\title{
LGR5 and Downstream Intracellular Signaling Proteins Play Critical Roles in the Cell Proliferation of Neuroblastoma, Meningioma and Pituitary Adenoma
}

\author{
Mina Hwang ${ }^{1 \dagger}$, Myung-Hoon Han ${ }^{2 \dagger}$, Hyun-Hee Park ${ }^{1 *}$, Hojin Choi ${ }^{1}$, Kyu-Yong Lee ${ }^{1}$, Young Joo Lee ${ }^{1}$, \\ Jae Min Kim², Jin Hwan Cheong' ${ }^{2}$, Je Il Ryu' ${ }^{2}$, Kyueng-Whan $\mathrm{Min}^{3}$, Young-Ha $\mathrm{Oh}^{3}$, Yong Ko ${ }^{4}$ and \\ Seong-Ho Koh ${ }^{1,5 *}$ \\ Departments of ${ }^{1}$ Neurology, ${ }^{2}$ Neurosurgery, and ${ }^{3}$ Pathology, Hanyang University Guri Hospital, Guri 11923, ${ }^{4}$ Department of \\ Neurosurgery, Hanyang University Medical Center, Seoul 04763, ${ }^{5}$ Department of Translational Medicine, Hanyang University \\ Graduate School of Biomedical Science \& Engineering, Seoul 04763, Korea
}

\begin{abstract}
Leucine-rich repeat-containing G-protein coupled receptor 5 (LGR5) has been reported to play critical roles in the proliferation of various cancer cells. However, the roles of LGR5 in brain tumors and the specific intracellular signaling proteins directly associated with it remain unknown. Expression of LGR5 was first measured in normal brain tissue, meningioma, and pituitary adenoma of humans. To identify the downstream signaling pathways of LGR5, siRNA-mediated knockdown of LGR5 was performed in SH-SY5Y neuroblastoma cells followed by proteomics analysis with 2-dimensional polyacrylamide gel electrophoresis (2D-PAGE). In addition, the expression of LGR5-associated proteins was evaluated in LGR5-inhibited neuroblastoma cells and in human normal brain, meningioma, and pituitary adenoma tissue. Proteomics analysis showed 12 protein spots were significantly different in expression level (more than two-fold change) and subsequently identified by peptide mass fingerprinting. A protein association network was constructed from the 12 identified proteins altered by $L G R 5$ knockdown. Direct and indirect interactions were identified among the 12 proteins. HSP 90-beta was one of the proteins whose expression was altered by LGR5 knockdown. Likewise, we observed decreased expression of proteins in the hnRNP subfamily following $L G R 5$ knockdown. In addition, we have for the first time identified significantly higher hnRNP family expression in meningioma and pituitary adenoma compared to normal brain tissue. Taken together, LGR5 and its downstream signaling play critical roles in neuroblastoma and brain tumors such as meningioma and pituitary adenoma.
\end{abstract}

Key words: LGR5, Neuroblastoma, Meningioma, Pituitary adenoma, hnRNP

\section{INTRODUCTION}

Cell surface receptor leucine-rich repeat-containing G-protein coupled receptor 5 (LGR5) is known as a stem cell marker in vari-

Received May 31,2019, Revised September 9, 2019,

Accepted September 19,2019

* To whom correspondence should be addressed.

Seong-Ho Koh, TEL: 82-31-560-2260, FAX: 82-31-560-2267

e-mail:ksh213@hanyang.ac.kr

Hyun-Hee Park, TEL: 82-31-560-2260, FAX: 82-31-560-2267

e-mail:newdiaz@hanmail.net

These authors contributed equally to the work. ous organs and tissues including the gut, stomach, hair follicles, mammary gland, kidney, ovary, and neural tissue [1,2]. LGR5 is a receptor for the R-spondin family of ligands and R-spondinmediated activation of LGR5 promotes Wnt/ $\beta$-catenin signaling. This process contributes to stem cell proliferation and self-renewal [3].

Wnt $/ \beta$-catenin signaling is also known to be associated with meningioma and pituitary adenoma [4]. Although a recent study reported that LGR5 was significantly overexpressed in pituitary adenomas compared to normal pituitaries, to the best of our knowledge, there are no further studies regarding the associa- 
tion between LGR5 and meningioma and pituitary adenoma [5]. Therefore, we wanted to identify the possible association between LGR5, as well as its downstream signaling proteins, and meningioma or pituitary adenoma tissue in comparison to normal brain tissue. Knockdown of $L G R 5$ would be a good way to confirm the intracellular signaling proteins that would be associated with LGR5 and how they are associated with human brain tumors. However, human brain tumor tissues obtained from patients cannot be used for the genetic modification of LGR5.

Neuroblastoma is the most common extracranial solid tumor in childhood cancer. It arises from neural crest progenitor cells and can develop anywhere along the sympathetic nervous system [6]. LGR5 is highly expressed in high-grade neuroblastomas, and LGR5-activated Wnt/ $\beta$-catenin signaling has been reported to play a critical role in neuroblastoma cell proliferation [7]. Indeed, shortinterfering RNA (siRNA)-mediated knockdown of LGR5 causes dramatic Wnt-independent apoptosis in neuroblastoma cells, suggesting that LGR5 is also required for the survival of neuroblastoma cells [7]. However, the specific intracellular proteins affected by knockdown of $L G R 5$ have not yet been described. Their identification will help to understand LGR5-related signaling pathways that may play crucial roles in neuroblastoma. Since meningioma and pituitary adenoma are associated with Wnt signaling, we further investigated the role of LGR5 on these tumors $[8,9]$.

Thus, the present study aimed to investigate whether the expression of LGR5 was different in meningioma and pituitary tumors compared with normal brain tissue in humans and to reveal proteins associated with LGR5 through siRNA-mediated knockdown of LGR5 in neuroblastoma cells. In addition, the roles of LGR5 and its downstream signaling proteins in the proliferation and survival of neuroblastoma cells were assessed. Finally, we evaluated the differences between LGR5-regulated proteins in meningioma and pituitary adenoma compared with normal brain tissue.

\section{MATERIALS AND METHODS}

\section{Preparation of human brain tumor tissues}

Human brain whole tissue lysates and brain tissue slides from normal adults were obtained from Novus Biologicals (Littleton, CO, USA). The brain tumor tissue samples were obtained from patients who underwent surgical resection of meningioma and pituitary adenoma at the department of neurosurgery of Hanyang University Medical Center (Seoul and Guri), Korea, from November 2016 in Guri and March 2017 in Seoul. Resected fresh tumor tissues were collected during surgery, these samples were then immediately submitted to the laboratory for storage at $-80^{\circ} \mathrm{C}$ in a facility which is located very near the operation room.
The study protocol was reviewed and approved by the Institutional Review Board in both Seoul (IRB No. 2017-02-016) and Guri Hospitals (IRB No. 2016-10-002) and adhered to the tenets of the Declaration of Helsinki. All patients provided informed written consent prior to participation in this study.

\section{MRI acquisition and histological sample preparation for light microscopy}

All brain MRI images were acquired using Philips 3.0 Tesla MRI scanners (Ingenia CX and Achieva, Philips Medical Systems, Best, The Netherlands) in both hospitals.

Fresh tumor tissues were fixed in $10 \%$ formalin for $24 \mathrm{~h}$, then grossed and placed for processing in an automated tissue processor (Thermo Fisher Scientific, Sydney, Australia). The tissue sections were sliced at $5 \mu \mathrm{m}$ thickness using a microtome. Hematoxylin and eosin (H\&E) stains were performed using a Tissue-Tek Prisma ${ }^{\circledR}$ E2D automated slide stainer (Sakura Finetek Japan Co., Ltd., Tokyo, Japan), following the respective standard protocols. All histopathological diagnoses established according to the World Health Organization (WHO) classification were additionally reviewed by two pathologists (K.W.M, Y.H.O) [10, 11].

\section{Cell culture of SH-SY5Y cells}

SH-SY5Y cells were obtained from the Korean Cell Line Bank (KCLB). Cells were plated on culture dishes and cultured in MEM medium [1× Minimum Essential Medium (MEM, Gibco, Frederick, MD, USA), 25 mM HEPES, $25 \mathrm{mM}$ sodium bicarbonate (Sigma-Aldrich, St. Louis, MO, USA), 90\%; heat-inactivated fetal bovine serum (FBS, Gibco), 10\%]. The media was changed every $3 \sim 4$ days, and cultures were maintained at $37^{\circ} \mathrm{C}$ under a humidified $5 \% \mathrm{CO}_{2}$ atmosphere.

\section{LGR5 knockdown}

SH-SY5Y cells were seeded at a density of $2.5 \times 10^{6} \mathrm{cells} / \mathrm{cm}^{2}$ in two six-well culture plates and cultured in antibiotic-free normal growth medium supplemented with FBS. Cells were incubated up to $60 \sim 80 \%$ confluency for $18 \sim 24$ h and $L G R 5$ knockdown was performed via $L G R 5$ siRNA transfection. First, $10 \mu \mathrm{M}$ of LGR5 siRNA duplex (Santa Cruz Biotechnology, Santa Cruz, CA, USA) diluted in opti-MEM medium (Gibco) was mixed with lipofectamine 2000 transfection reagent (Invitrogen, Carlsbad, CA, USA) diluted in opti-MEM medium (Gibco) at a ratio of $1: 1$ according to the manufacturer's instructions. After $5 \mathrm{~m}$ incubation, the mixed solution was added to cells at different concentrations $(30,40,50,80$, and $160 \mu \mathrm{M})$ with culture medium. The transfected cells were analyzed after $24 \mathrm{~h}$ at $37^{\circ} \mathrm{C}$ in a $\mathrm{CO}_{2}$ incubator. A control using $10 \mu \mathrm{M}$ siRNA duplex (Santa Cruz) 
was produced by the same method. LGR5 siRNA is a pool of 3 different siRNA duplexes. A, 5'-GGAUGACAAUGCGUUAACAtt-3' (sense), 5'-UGUUAACGCAUUGUCAUCCtt-3' (antisense); B, 5'-CUCCAACCUUAAAGAAC-UAtt-3' (sense ), 5'-UAGUUCUUUAAGGUUGGAGtt-3' (anti-sense); and C, 5'-GAA-AGAUGCUGGAAUGUUUtt-3' (sense), 5'-AAACAUUCCAGCAUCUUUCtt-3' (anti-sense). Control siRNA duplex: 5'-UUCUCCGAACGUGUCACGUtt-3' (sense), 5'-ACGUGACACGUUCGGAGAAtt-3' (anti-sense).

\section{Western blot analysis}

Expression levels of LGR5, active $\beta$-catenin, cyclin D1, c-myc, hnRNPA2B1, and hnRNPH3 in human normal and collected brain tumor tissues and knockdown of LGR5 in SH-SY5Y cells were confirmed by western blot analysis [12, 13]. Briefly, sample tissues and cells were washed twice with cold D-PBS and incubated for $30 \mathrm{~m}$ on ice after the addition of lysis buffer (RIPA II cell lysis buffer $1 \times$ with Triton, without EDTA; $1 \mathrm{mM}$ phenylmethylsulfonyl fluoride (PMSF); $1 \mathrm{mM}$ sodium fluoride (NaF); $1 \mathrm{mM}$ sodium orthovanadate $\left(\mathrm{Na}_{3} \mathrm{VO}_{4}\right)$; and $0.5 \%$ protease inhibitor cocktail $1 \times$ ). Next, the tissues and cells were sonicated (Sonoplus, Bandelin Electronics, Berlin, Germany) and incubated for $30 \mathrm{~m}$ on ice. The resulting lysates were then centrifuged at 16,200×g for 15 $\mathrm{m}$ and the protein concentrations of lysates were determined using a Bio-Rad (Hercules, CA, USA) protein assay kit. Normal adult human brain whole lysates (Novus Biologicals) and lysate samples containing equal amounts of protein (tissues, $30 \mu \mathrm{g}$; cells, $25 \mu \mathrm{g}$ ) were resolved by $4 \sim 12 \%$ sodium dodecyl sulfate-polyacrylamide gel electrophoresis (SDS-PAGE, Invitrogen). After SDS-PAGE, proteins were transferred to polyvinylidene fluoride membranes (Millipore, Bedford, MA, USA). Membranes were blocked with $2 \%$ skimmed milk and incubated with a specific primary antibody. The antibodies used in these experiments were as follows: LGR5 (1:200, Santa Cruz), active $\beta$-catenin (1:1000, Cell Signaling, Beverly, MA, USA), cyclin D1 (1:2000, Cell Signaling), c-myc (1:1000, Cell Signaling), GAPDH (1:4000, Cell Signaling), hnRNPA2B1 $(0.75 \mu \mathrm{g} / \mathrm{ml}$, Abcam, Burlingame, CA, USA), and hnRNPH3 (1:75, Santa Cruz). After washing membranes three times with Tris-buffered saline containing $0.1 \%$ Tween-20 (TBST), membranes were hybridized with Horseradish Peroxidase (HRP)-conjugated antimouse antibody (1:2000, Jackson ImmunoResearch Laboratories, Inc., West Grove, PA, USA) or HRP-conjugated anti-rabbit antibody (1:2000, Jackson ImmunoResearch Laboratories) followed by using a West-Q Chemiluminescent Substrate Kit (GenDEPOT, Katy, TX, USA). Blots were quantified with an image analyzer (ImageQuant LAS 4000; GE Healthcare, Little Chalfont, UK).

\section{Immunohistochemistry}

For immunohistochemistry, human brain normal and tumor tissues (meningioma and pituitary adenoma) were fixed with paraffin. First, fixed tissues were subjected to deparaffinization and hydration processes. The tissues were washed with xylene 4 times, 100\% ethanol 2 times, 95\% ethanol, 80\% ethanol, 70\% ethanol, 50\% ethanol, and auto-distilled water for $3 \mathrm{~m}$ each step. Antigen retrieval was induced from deparaffinized and hydrated tissues using pre-heated $0.01 \mathrm{M}$ sodium citrate ( $\mathrm{pH}$ 6). The tissues were permeabilized with $0.5 \%$ Triton X-100 (Sigma-Aldrich) in $0.01 \mathrm{M}$ PBS for $5 \mathrm{~m}$. Next, $\mathrm{H}_{2} \mathrm{O}_{2}$ was used to block endogenous peroxidase activity of the tissues for $10 \mathrm{~m}$ and 10\% FBS (Gibco) was used as the blocking solution for $1 \mathrm{~h}$. The tissues were then incubated overnight with specific primary antibodies in $0.5 \%$ FBS at $4{ }^{\circ} \mathrm{C}$. The antibodies used in these experiments were hnRNPH3 (1:300, Santa Cruz) and LGR5 (1:60, Abcam). The following day, the tissues were washed and incubated with secondary antibodies in $0.5 \%$ FBS for $3 \mathrm{~h}$. Tetramethylrhodamine goat anti-mouse IgG (Invitrogen) and Alexa Fluor ${ }^{\mathrm{TM}} 488$ goat anti-rabbit IgG (Invitrogen) were used as secondary antibodies. Finally, the tissues were mounted with DAPI mounting solution (Vector Laboratories Inc., Burlingame, CA, USA). Throughout the procedure, the tissues were washed three times with $0.01 \mathrm{M}$ PBS between each step. Immunohistochemically positive cells were identified under a confocal fluorescence microscope (Nanoscope systems Inc., Daejeon, Korea).

\section{Proteomics}

\section{Protein sample preparation}

SH-SY5Y cells treated with LGR5 or control siRNA were collected and washed several times with D-PBS to remove salts and lipids. The cells were then lysed in lysis buffer consisting of $7 \mathrm{M}$ urea and $2 \mathrm{M}$ thiourea containing $4 \%(\mathrm{w} / \mathrm{v}) 3$ - [(3-cholamidopropyl) dimethylammonio]-1-propanesulfonate (CHAPS), 1\% (w/v) dithiothreitol (DTT), 2\% (v/v) pharmalyte, and $1 \mathrm{mM}$ benzamidine. The cells were then sonicated as described above and extracted by vortexing at room temperature for $1 \mathrm{~h}$. Next, the lysates were subjected to centrifugation at $15,000 \times \mathrm{g}$ for $1 \mathrm{~h}$ at $4^{\circ} \mathrm{C}$, after which the insoluble material was discarded and the soluble fraction was saved for two-dimensional gel electrophoresis (2-DE). Protein concentrations were calculated by using the Bradford assay.

\section{D PAGE}

Protein samples prepared as described above were added to $0.5 \%$ Immobilized pH gradient (IPG) buffer and re-hydrated with IPG dry strips (3 10 NL IPG, $13 \mathrm{~cm}$, GE Healthcare, Buckinghamshire, 
UK) for 16 20 h. Next, isoelectric focusing (IEF) was performed on the re-hydrated samples using an Ettan IPGphor 3 (GE Healthcare) according to the manufacturer's instructions. During IEF, the voltage was increased to $8,000 \mathrm{~V}$ over $7 \mathrm{~h}$, followed by maintenance at a constant $8,000 \mathrm{~V}$ for sample entry, and focusing was completed after $55 \mathrm{kV}$. Prior to the 2 nd dimension separation, the isoelectric-focused strips were incubated in equilibration buffer (75 mM Tris-Cl, pH 8.8, containing $6 \mathrm{M}$ urea, 2\% SDS, $0.002 \% 1 \%$ Bromophenol blue stock solution, and $29.3 \%$ glycerol) containing 1\% DTT (Sigma-Aldrich) for $15 \mathrm{~m}$ and then the same procedure was repeated with equilibration buffer containing $2.5 \%$ iodoacetamide (Sigma-Aldrich) for $15 \mathrm{~m}$. The equilibrated strips were then fixed onto large SDS-PAGE gels $(13 \times 18 \mathrm{~cm}, 12.5 \%)$ using an agarose sealing solution. 2D-PAGE was performed using a SE600 2D system (GE Healthcare) according to the manufacturer's instructions. Briefly, 2D gels were run at $4^{\circ} \mathrm{C} 10 \mathrm{~mA}$ for $1.5 \mathrm{~h}, 30 \mathrm{~mA}$ for 3 $\mathrm{h}$, and $40 \mathrm{~mA}$ for $2 \mathrm{~h}$.

\section{Image analysis}

Completed 2D-PAGE gels were stained using Coomassie brilliant blue R-350 (CBB; GE Healthcare) and scanned as computer images. The collected images were quantitatively analyzed by
ImageMasterTM 2D Platinum 7.0 software (GE Healthcare) according to the manufacturer's instructions. The intensity of each protein spot was normalized to the total intensity of all validated protein spots. The expression of the selected protein spots had at the least a two-fold significant difference compared to control samples.

\section{Peptide mass fingerprinting (PMF)}

Proteins were identified by peptide mass fingerprinting (PMF). Protein spots were excised, digested with trypsin (Promega, Madison, WI, USA), and mixed with a cyano-4-hydroxycinnamic acid in 50\% acetonitrile/0.1\% TFA for MALDI-TOF analysis (Microflex LRF 20, BrukerDaltonics, Billerica, MA, USA) as described by Fernandez et al [14]. Spectra were collected from 300 shots per spectrum over the $600 \sim 3000 \mathrm{~m} / \mathrm{z}$ range and calibrated by a two-point internal calibration using trypsin auto-digestion peaks (m/z 842.5099, 2211.1046). The peak list was generated by Flex Analysis 3.0 software, with a peak selection threshold of 500 for the minimum resolution of monoisotopic mass and 5 for $\mathrm{S} / \mathrm{N}$. Protein identification by PMF was performed using the search program MASCOT, developed by Matrix Science (http://www. matrixscience.com/). The following parameters were used for the
A
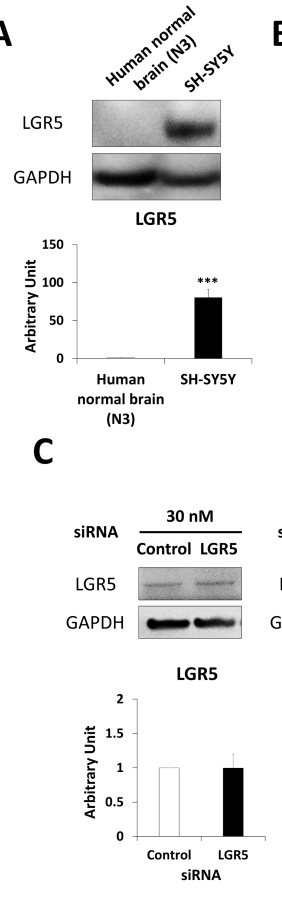

B
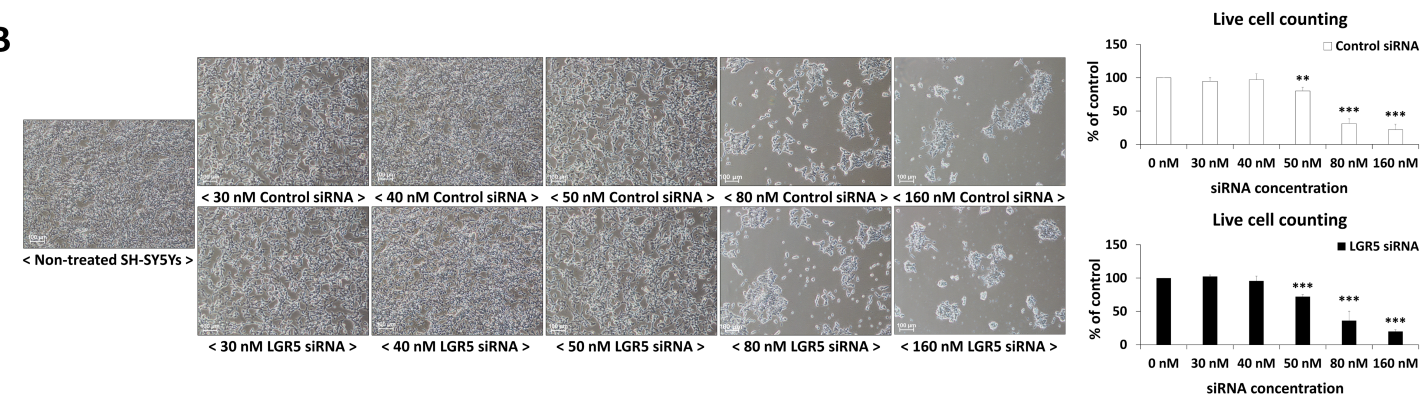

D
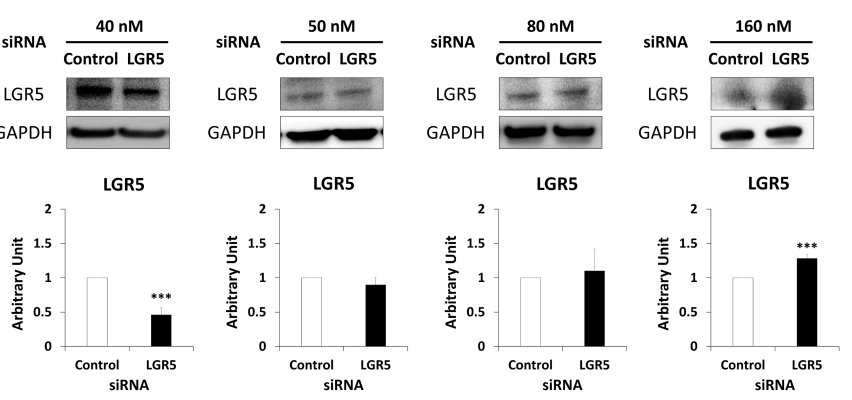
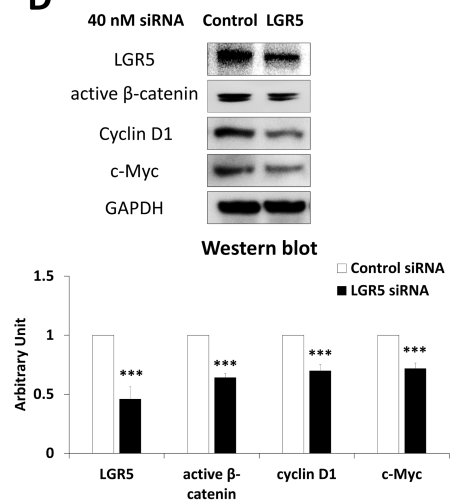

Fig. 1. Inhibition of LGR5 in SH-SY5Y neuroblastoma cells. (A) Expression of LGR5 in human normal brain (N3 of Table 1) and SH-SY5Y neuroblastoma cells. (B) Morphology of non-treated SH-SY5Y and control/LGR5 siRNA-treated SH-SY5Y, and live cell counting graphs of each groups in \% of non-treated SH-SY5Y. (C) Western blotting results of SH-SY5Y treated with different concentrations of $L G R 5$ siRNA (30, 40, 50, 80, and 160 nM). (D) Confirmation of $L G R 5$ knockdown and downregulation of Wnt/ $\beta$-catenin down-signal with $40 \mathrm{nM} L G R 5$ siRNA in SH-SY5Y by western blotting. 
database search: trypsin as the cleaving enzyme, a maximum value of one missed cleavage, iodoacetamide (Cys) as a complete modification, oxidation (Met) as a partial modification, monoisotopic mass, and a mass tolerance for peptide ion $(\mathrm{m} / \mathrm{z})$ of $\pm 0.1 \mathrm{Da}$. PMF acceptance criteria were based on probability scoring.

\section{Bioinformatics analysis}

A network of associated proteins was constructed using the Search Tool for the Retrieval of Interacting Genes/Proteins (STRING) database version 11.0 (http://www.string-db.org/). The rationale and methods underlying the use of STRING are available elsewhere [15]. We used the confidence setting between network edges, where line thickness between two proteins is indicative of the strength of the data supporting the association. We activated all interaction sources including text-mining, experiments, databases, co-expression, neighborhood, gene fusion, and co-occurrences. The minimum required interaction score was set at 0.400 (medium confidence), which meant that any interaction power between two proteins that was below the level of medium confidence was excluded from our analysis.

\section{Statistical analysis}

All data are expressed as the means \pm SD of three or more independent experiments. Statistical comparisons between different treatment groups were performed with the Student's t-test and one-way analysis of variance (ANOVA) followed by Tukey's honestly significant difference (HSD) test. p-values less than 0.05 were considered statistically significant.

\section{RESULTS}

\section{Knockdown of LGR5 in SH-SY5Y cells}

SH-SY5Y cells showed significantly higher LGR5 expression compared to human normal brain tissue (Fig. 1A). Different concentrations of $L G R 5 \mathrm{siRNA}$, ranging from $30 \mathrm{nM}$ to $160 \mathrm{nM}$, were used to see if knockdown of $L G R 5$ could be induced selectively
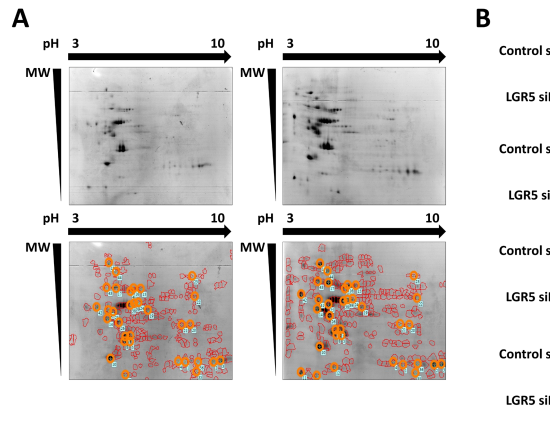

D

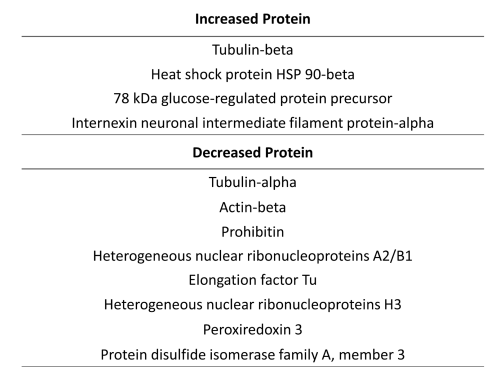

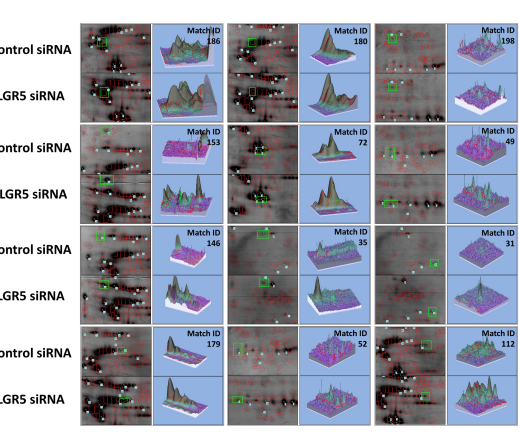

C

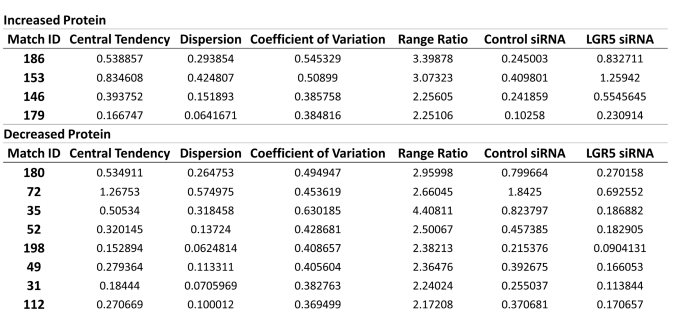

$F$

E

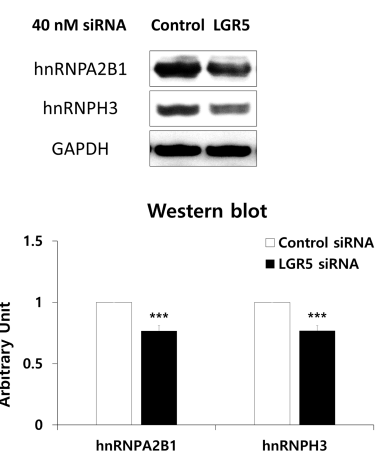

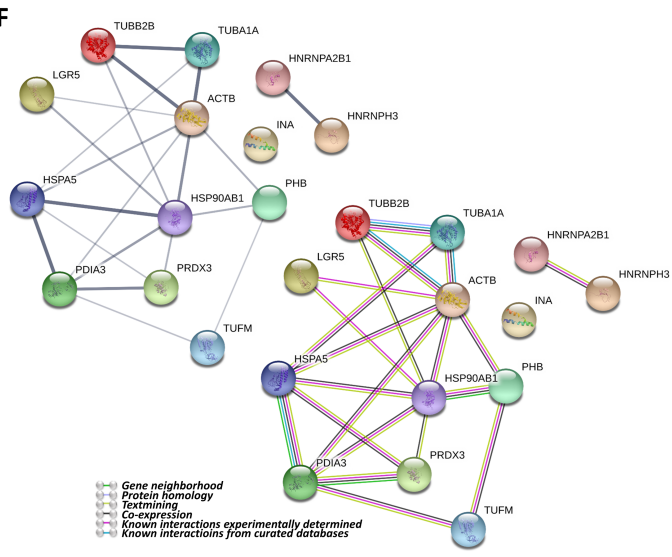

Fig. 2. Proteomic and bioinformatic analysis of LGR5 knockdown in SH-SY5Y cells. (A) Coomassie brilliant blue R-350 stained gels after 2D-PAGE. Protein spots in SH-SY5Y cells after treatment with control siRNA or LGR5 siRNA. Common landmarks of protein spots in the SH-SY5Y cells after treatment with control siRNA and $L G R 5$ siRNA are indicated. (B) Identification of protein spots. Protein spots exhibiting a change greater than twofold in the expression in SH-SY5Y cells treated with LGR5 siRNA compared to control cells. (C) Detailed information of the 12 selected protein spots. (D) Proteins with increased and decreased expression after LGR5 inhibition compared to control-treated cells. (E) Identification of different expression levels of hnRNPA2B1 and hnRNPH3 in SH-SY5Y cells after treatment with LGR5 siRNA or control siRNA by western blotting. (F) LGR5-associated protein-protein interaction network. An LGR5-associated protein-protein interaction network was constructed using a bioinformatics approach. Circles indicate LGR5 and the 12 proteins found to be associated with LGR5 in neuroblastoma cells by a proteomics approach. The thickness of the line between any two proteins represents the degree of confidence in the interaction between the two proteins, with thicker lines indicating higher confidence (left upper). The types of interactions between proteins are represented by action types and effects (right lower). 
(Fig. 1B and 1C). Toxic effects were observed in SH-SY5Y cells in case of both $50 \mathrm{nM}$ control and LGR5 siRNAs (Fig. 1B). Western blotting indicated that $40 \mathrm{nM} L G R 5$ siRNA could effectively knockdown $L G R 5$ expression in neuroblastoma cells (Fig. 1C). It was also confirmed that the expression of active $\beta$-catenin, cyclin D1 and c-Myc, which are proteins that are downstream of LGR5, were also significantly decreased in SH-SY5Y cells after treatment with LGR5 siRNA compared to control siRNA (Fig. 1D).

A

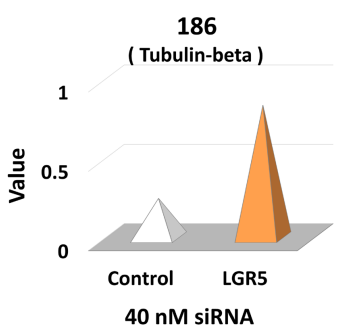

146

( $78 \mathrm{kDa}$ glucose-regulated protein precursor)

$$
1
$$

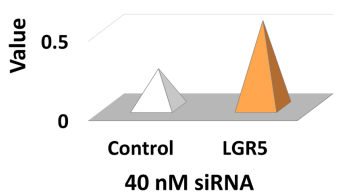

B
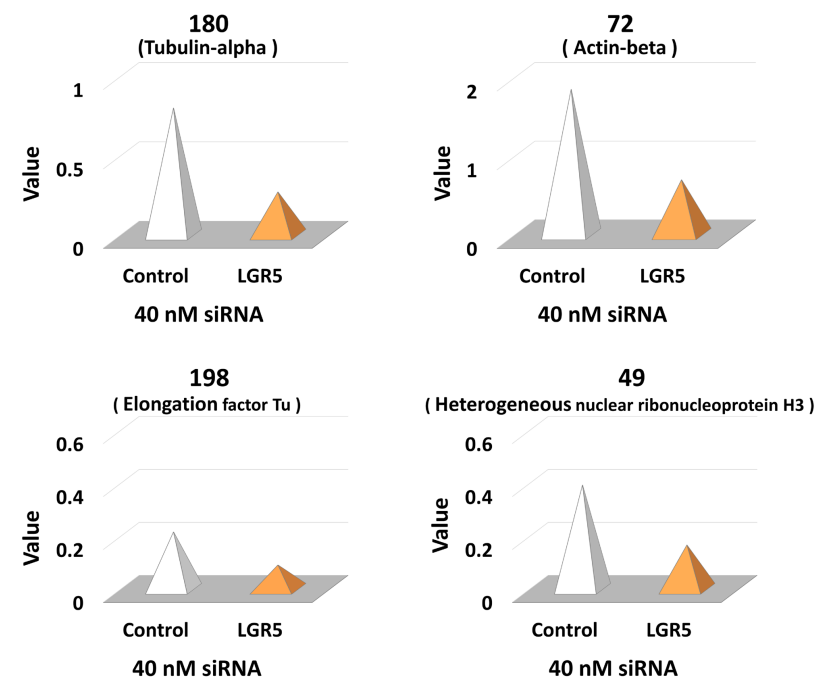

\section{Identification of differentially regulated proteins after} LGR5 knockdown in SH-SY5Y cells

Proteomics was performed using 2D-PAGE to evaluate differences in the expression of intracellular proteins in neuroblastoma cells with or without $L G R 5$ knockdown (Fig. 2A).

Multiple landmarks were selected for the classification of protein spots. Based on the landmarks, 12 protein spots were identified that exhibited a greater than two-fold increase or decrease in expression in SH-SY5Y cells treated with LGR5 siRNA compared to cells transfected with control siRNA (Fig. 2B). Detailed information, including the expression ratios of the proteins identified, is

Fig. 3. Detailed information of protein spots exhibiting a change greater than two-fold in the expression in- SH-SY5Y cells treated with $L G R 5$ siRNA compared to control cells. (A) Identification of proteins with a greater than two-fold increase in the expression in SH-SY5Y cells treated with LGR5 siRNA compared to control-treated cells. (B) Identification of proteins with a greater than two-fold decrease in the expression in SH-SY5Y cells treated with LGR5 siRNA compared to control-treated cells. 
presented in Fig. 2C).

\section{Identification of proteins altered by LGR5 knockdown us- ing MALDI-TOF mass spectrometry}

A total of 12 protein spots altered by LGR5 knockdown were excised and analyzed using MALDI-TOF mass spectrometry. Closely matched proteins were identified and selected based on the MASCOT database (Fig. 3).

Among the 12 proteins identified, the expression of four proteins was increased in neuroblastoma cells with LGR5 knockdown while the expression of eight proteins was decreased (Fig. 2D). Specifically, the proteins with increased expression comprised tubulin-beta, heat shock protein (HSP) 90-beta, 78 kDa glucoseregulated protein precursor (GRP78), and internexin neuronal intermediate filament protein-alpha ( $\alpha$-internexin). On the contrary, proteins with decreased expression comprised alpha-tubulin, beta-actin, prohibitin, heterogeneous nuclear ribonucleoproteins A2/B1 (hnRNPA2B1), elongation factor Tu (EF-Tu), heterogeneous nuclear ribonucleoprotein $\mathrm{H} 3$ (hnRNPH3), peroxiredoxin 3 , and protein disulfide isomerase family A, member 3 (PDIA3). Based on the results, we additionally identified that hnRNPA2B1 and hnRNPH3 were decreased in neuroblastoma cells after $L G R 5$ knockdown using western blotting (Fig. 2E).

\section{Protein-protein interactions associated with LGR5 in neu- roblastoma cells}

Direct or indirect interactions with specific interaction types were identified among the 12 proteins that were associated with LGR5 in neuroblastoma cells (Fig. 2F). As expected, a strong protein interaction was observed between each protein family, which included cytoskeleton proteins, HSPs, and hnRNPs. Interestingly, the HSP family exhibited strong protein interactions with cytoskeleton proteins and PDIA3. In addition, peroxiredoxin 3 was found to interact strongly with PDIA3. However, due to the lack of previous information on proteins associated with LGR5, especially in neuroblastoma cells, no significant relationships between LGR5 and the 12 differentially expressed proteins were identified.

\section{Clinical, radiographic, and histologic characteristics of study subjects}

In the present study, we included three human tissues from normal brain, five benign meningiomas (WHO grade I), and five pituitary adenomas. Detailed information of patients and tumor samples is presented in Table 1.

Representative radiographic and histological findings of meningothelial, fibrous, and transitional meningioma, and pituitary adenoma in study subjects are shown in Fig. 4.

LGR5 expression in human brain tumor tissue samples

LGR5 expression was measured in normal brain, benign menin-

Table 1. Patient description and tumor sample characteristics

\begin{tabular}{|c|c|c|c|c|c|c|c|c|c|}
\hline Sample & Sex & Age & Tumor type & Location & $\begin{array}{c}\text { Sample } \\
\text { Concen- } \\
\text { tration } \\
(\mu \mathrm{g} / \mu \mathrm{l})\end{array}$ & $\begin{array}{c}\text { Sample } \\
\text { volume } \\
(\mu \mathrm{l})\end{array}$ & $\begin{array}{l}\text { Ki-67 } \\
\text { index }\end{array}$ & p53 & $\begin{array}{l}\text { Underlying } \\
\text { disease }\end{array}$ \\
\hline N1 & M & 66 & Normal brain (human adult) & Whole brain & 4.47 & 150 & & & \\
\hline $\mathrm{N} 2$ & M & 57 & Normal brain (human adult) & Whole brain & 4.32 & 150 & & & \\
\hline N3 & M & 82 & Normal brain (human adult) & Whole brain & 4.89 & 150 & & & \\
\hline Group 1 & \multicolumn{9}{|c|}{ Meningioma, WHO grade I } \\
\hline 1 & M & 61 & Meningioma, meningothelial & Parasagittal, right & 28.62 & 110 & $<1 \%$ & $(-)$ & Alcohol, smoking \\
\hline 2 & $\mathrm{~F}$ & 64 & Meningioma, fibrous & Falx, right & 29.13 & 200 & $1 \sim 2 \%$ & $(-)$ & $(-)$ \\
\hline 3 & $\mathrm{~F}$ & 64 & Meningioma, meningothelial & CPA, right & 23.01 & 100 & $1 \%$ & $(-)$ & $(-)$ \\
\hline 4 & $\mathrm{~F}$ & 56 & Meningioma, transitional & Convexity, right & 41.67 & 600 & $<1 \%$ & $15 \%$ & HTN, DM \\
\hline 5 & $\mathrm{~F}$ & 74 & $\begin{array}{l}\text { Meningioma, } \\
\text { transitional }\end{array}$ & Falx, both & 30.99 & 400 & $<1 \%$ & $30 \%$ & $(-)$ \\
\hline Group 2 & \multicolumn{9}{|c|}{ Pituitary adenoma } \\
\hline 6 & $\mathrm{~F}$ & 51 & Pituitary adenoma & Pituitary gland & 19.47 & 100 & $<1 \%$ & $1 \%$ & $(-)$ \\
\hline 7 & $\mathrm{~F}$ & 42 & $\begin{array}{l}\text { Pituitary adenoma, ACTH } \\
\text { producing }\end{array}$ & Pituitary gland & 17.94 & 90 & $<1 \%$ & $1 \%$ & Cushing disease \\
\hline 8 & M & 51 & Pituitary adenoma & Pituitary gland & 20.19 & 110 & $<1 \%$ & $(-)$ & $\mathrm{DM}$ \\
\hline 9 & M & 38 & Pituitary adenoma & Pituitary gland & 20.31 & 50 & $1 \%$ & $1 \%$ & $(-)$ \\
\hline 10 & $\mathrm{~F}$ & 53 & Pituitary adenoma & Pituitary gland & 18.00 & 90 & $<1 \%$ & $5 \%$ & $(-)$ \\
\hline
\end{tabular}

WHO, world health organization; CPA, cerebellopontine angle; HTN, hypertension; DM, diabetes mellitus; ACTH, adrenocorticotropic hormone. 
A
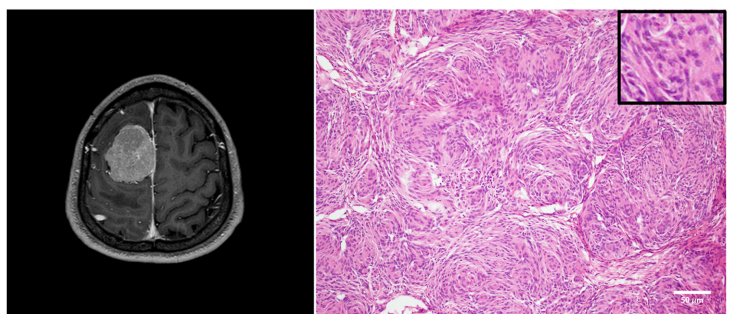

B

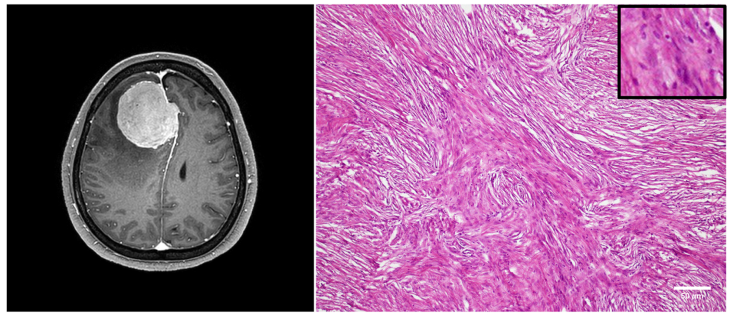

C

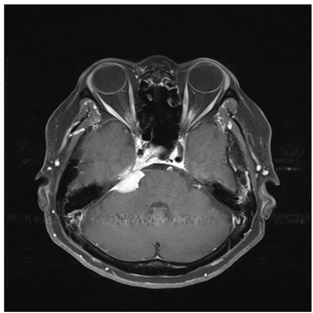

D

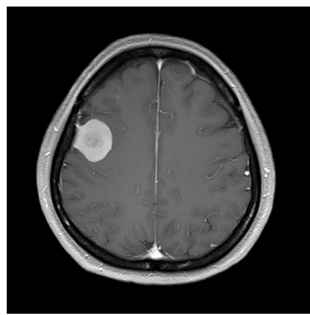

E

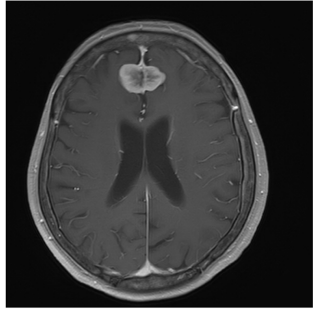

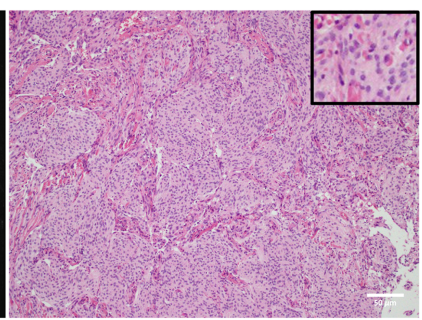
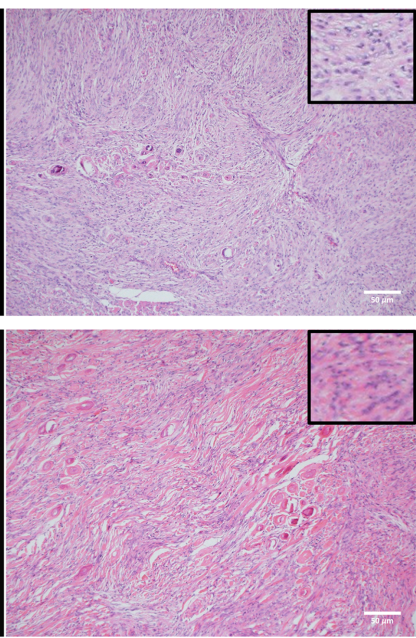

$\mathbf{F}$
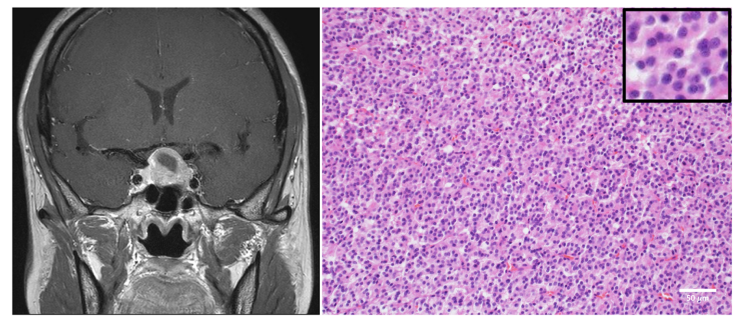

G

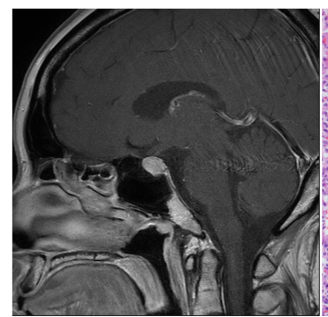

H

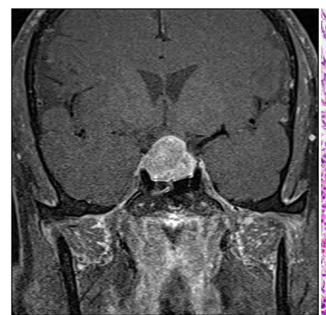

I

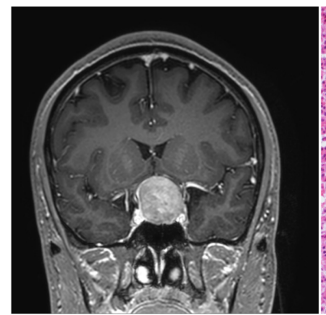

J

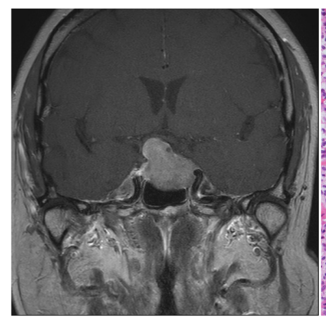

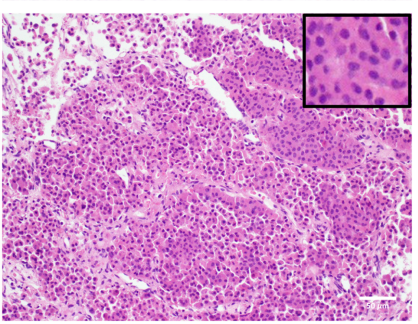
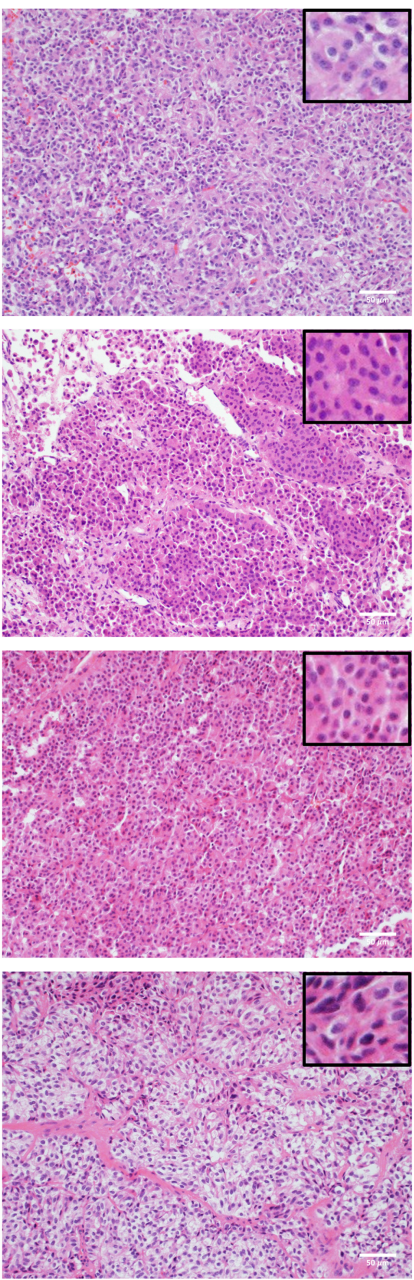

Fig. 4. Radiographic and pathologic findings of the subjects included in the study. (A) Brain MRI of a 61-year-old male (sample number 1) with parasagittal meningioma. Histological staining of human brain tumor (sample number 1) showing features of meningothelial meningioma (original magnification $\times 100$ ). Scale bar: $50 \mu \mathrm{m}$. (B) Brain MRI of a 64-year-old female (sample number 2) with falx meningioma. Histological staining of human brain tumor (sample number 2) showing features of fibrous meningioma (original magnification $\times 100$ ). Scale bar: $50 \mu \mathrm{m}$. (C) Brain MRI of a 64-year-old female (sample number 3) with CPA meningioma. Histological staining of human brain tumor (sample number 3) showing features of meningothelial meningioma (original magnification $\times 100$ ). Scale bar: $50 \mu \mathrm{m}$. (D) Brain MRI of a 56-year-old female (sample number 4) with convexity meningioma. Histological staining of a human brain tumor (sample number 4) showing features of transitional meningioma (original magnification $\times 100$ ). Scale bar: $50 \mu \mathrm{m}$. (E) Brain MRI of a 74-year-old female (sample number 5) with falx meningioma. Histological staining of human brain tumor (sample number 5) showing features of transitional meningioma (original magnification $\times 100$ ). Scale bar: $50 \mu \mathrm{m}$. (F) Brain MRI of a 51-year-old female (sample number 6) with pituitary adenoma. Histological staining of human brain tumor (sample number 6) showing features of pituitary adenoma (original magnification×200). Scale bar: $50 \mu \mathrm{m}$. (G) Brain MRI of a 42-year-old female (sample number 7) with pituitary adenoma. Histological staining of human brain tumor (sample number 7) showing features of pituitary adenoma (original magnification $\times 200$ ). Scale bar: $50 \mu \mathrm{m}$. (H) Brain MRI of a 51 -year-old male (sample number 8) with pituitary adenoma. Histological staining of human brain tumor (sample number 8) showing features of pituitary adenoma (original magnification $\times 200$ ). Scale bar: $50 \mu \mathrm{m}$. (I) Brain MRI of a 38-year-old male (sample number 9) with pituitary adenoma. Histological staining of human brain tumor (sample number 9) showing features of pituitary adenoma (original magnification $\times 200$ ). Scale bar: $50 \mu \mathrm{m}$. (J) Brain MRI of a 53 -year-old female (sample number 10) with pituitary adenoma. Histological staining of human brain tumor (sample number 10) showing features of pituitary adenoma (original magnification $\times 200$ ). Scale bar: $50 \mu \mathrm{m}$. MRI, magnetic resonance imaging; CPA, cerebellopontine angle. 
gioma, and pituitary adenoma tissues. Fig. 5A shows differences of LGR5 protein expression, analyzed by western blotting, between normal, benign meningioma, and pituitary adenoma. It was found that LGR5 expression was significantly higher in meningioma and pituitary adenoma, compared to normal brain tissue.

\section{Expression of LGR5 and hnRNP proteins in meningioma and pituitary adenoma tissues}

We also evaluated hnRNPA2B1 and hnRNPH3 expression levels in benign meningioma and pituitary adenoma tissues compared to normal brain tissue by using western blotting (Fig. 5A). We identified significantly higher expression of hnRNPA2B1 and hnRNPH3 in benign meningioma and pituitary adenoma compared to normal. Detailed information on protein expression levels of LGR5, hnRNPA2B1, and hnRNPH3 in each meningioma and pituitary adenoma tissue sample compared to normal is presented in Fig. 6.

The distribution of LGR5 and hnRNPH3 was identified in human normal brain and benign meningioma and pituitary adenoma with immunohistochemical analysis (Fig. 5B). We observed that LGR5 and hnRNPH3 were co-expressed in meningioma and pituitary adenoma, indicating that both LGR5 and hnRNPs are as-

A

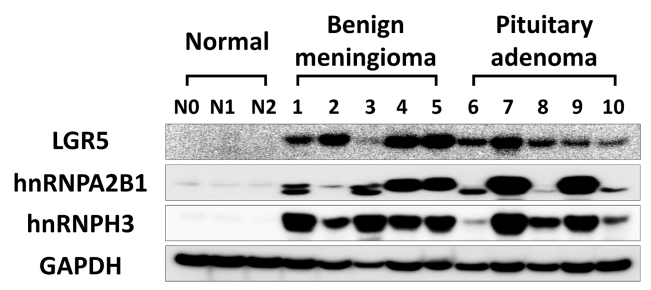

LGR5

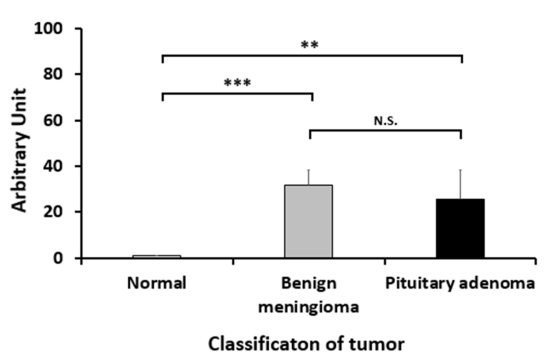

hnRNPA2B1

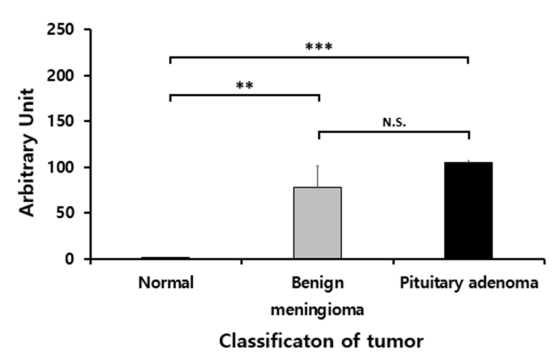

hnRNPH3

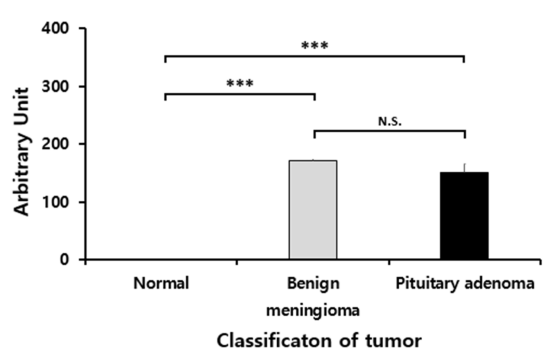

Immunohistochemistry
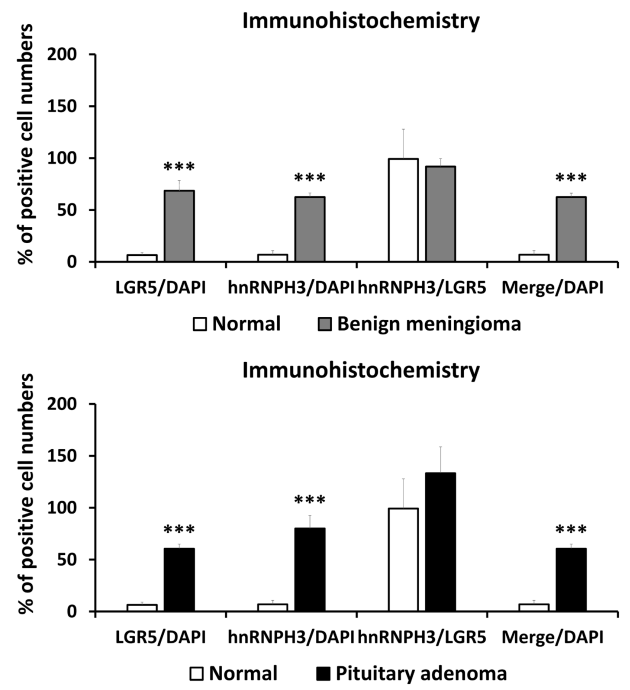

Fig. 5. Expression of LGR5, hnRNPA2B1, and hnRNPH3 proteins in human normal, benign meningioma, and pituitary adenoma tissues, and immunohistochemistry for LGR5 and hnRNPH3 in meningioma and pituitary adenoma tissues with immunofluorescence confocal microscopy. (A) Comparison of expression levels of LGR5, hnRNPA2B1, and hnRNPH3 between normal, benign meningioma, and pituitary adenoma by western blotting. (B) Confocal images of the human normal brain (top), meningioma (middle) and pituitary adenoma (bottom) tissues stained with antibodies against LGR5 (green) and hnRNPH3 (red). Scale bar: $20 \mu \mathrm{m}$. The number of LGR5 ${ }^{+} / \mathrm{hnRNPH}^{+}$cells per DAPI positive cells and hnRNPH3 ${ }^{+}$cells per LGR5 positive cells was counted and expressed as \%. 

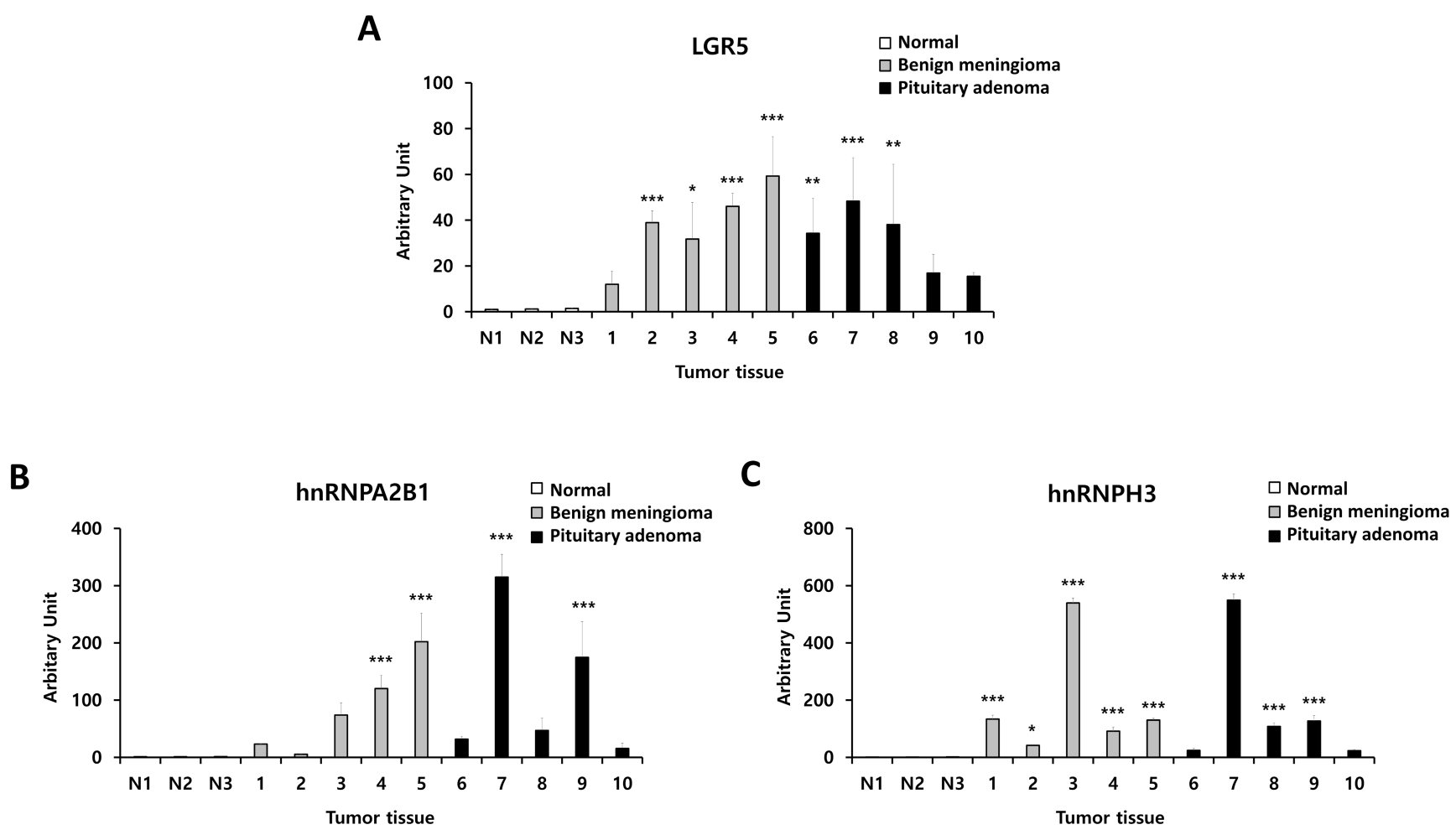

Fig. 6. Detailed information on expression levels of LGR5, hnRNPA2B1, and hnRNPH3 in each human benign meningioma and pituitary adenoma tissue sample compared to normal samples. (A) LGR5, (B) hnRNPA2B1, and (C) hnRNPH3.

sociated with human meningioma and pituitary adenoma.

\section{Proposed mechanisms for the role of LGR5 and hnRNPs in human meningioma and pituitary adenoma.}

In considering our results, we propose a possible novel association between LGR5 and the hnRNP family in human meningioma and pituitary adenoma (Fig. 7). The detailed mechanisms of Wnt signaling and splicing, which were not proved in the study, were referenced from previous studies [16-19]. R-spondin-mediated activation of LGR5 promotes Wnt/ $\beta$-catenin signaling and the activation of Wnt target genes may also affect activation of the hnRNP family. This process may lead to alternative gene transcription, splicing, and post-transcriptional modification of pre-mRNA processing and result in tumorigenesis in human meningioma and pituitary adenoma.

\section{DISCUSSION}

A few previous studies reported that LGR5 was related to poor prognosis or proliferation of intra-axial brain malignancy such as glioma [20,21]. However, to the best of our knowledge, there is a lack of studies regarding the association between LGR5 and extraaxial brain tumors such as meningioma and pituitary adenoma. In addition, LGR5 is closely associated with Wnt signaling, and previous studies have reported that both meningioma and pituitary adenoma are associated with Wnt signaling $[8,9]$. Therefore, we wanted to investigate the association between LGR5 and human meningioma and pituitary adenoma and confirmed that LGR5 was increased in meningioma and pituitary tumors compared with normal brain tissue (Fig. 4 and 5A). Initially, we evaluated the proteins which are associated with $L G R 5$ knockdown by proteomics analysis in SH-SY5Y neuroblastoma cells (Fig. 2). We used SH-SY5Y cells for our study because they are relatively easy to obtain, widely used, and derived from an extra-axial solid tumor which originated from neuroblasts of the neural crest [22]. After we identified proteins which were related to knockdown of $L G R 5$ in neuroblastoma cells, we extended our experiments to human meningioma and pituitary adenoma.

In the present study, we initially identified 12 proteins in the SHSY5Y neuroblastoma cell line that were differentially expressed following knockdown of LGR5 (Fig. 2D), which is an important factor associated with Wnt/ $\beta$-catenin signaling [7]. In addition, we identified significantly higher hnRNP family expression, which was affected by LGR5 inhibition in neuroblastoma cells, and human benign meningioma and pituitary adenoma tissue more than in normal human brain tissue (Fig. 5A). Our findings led us 


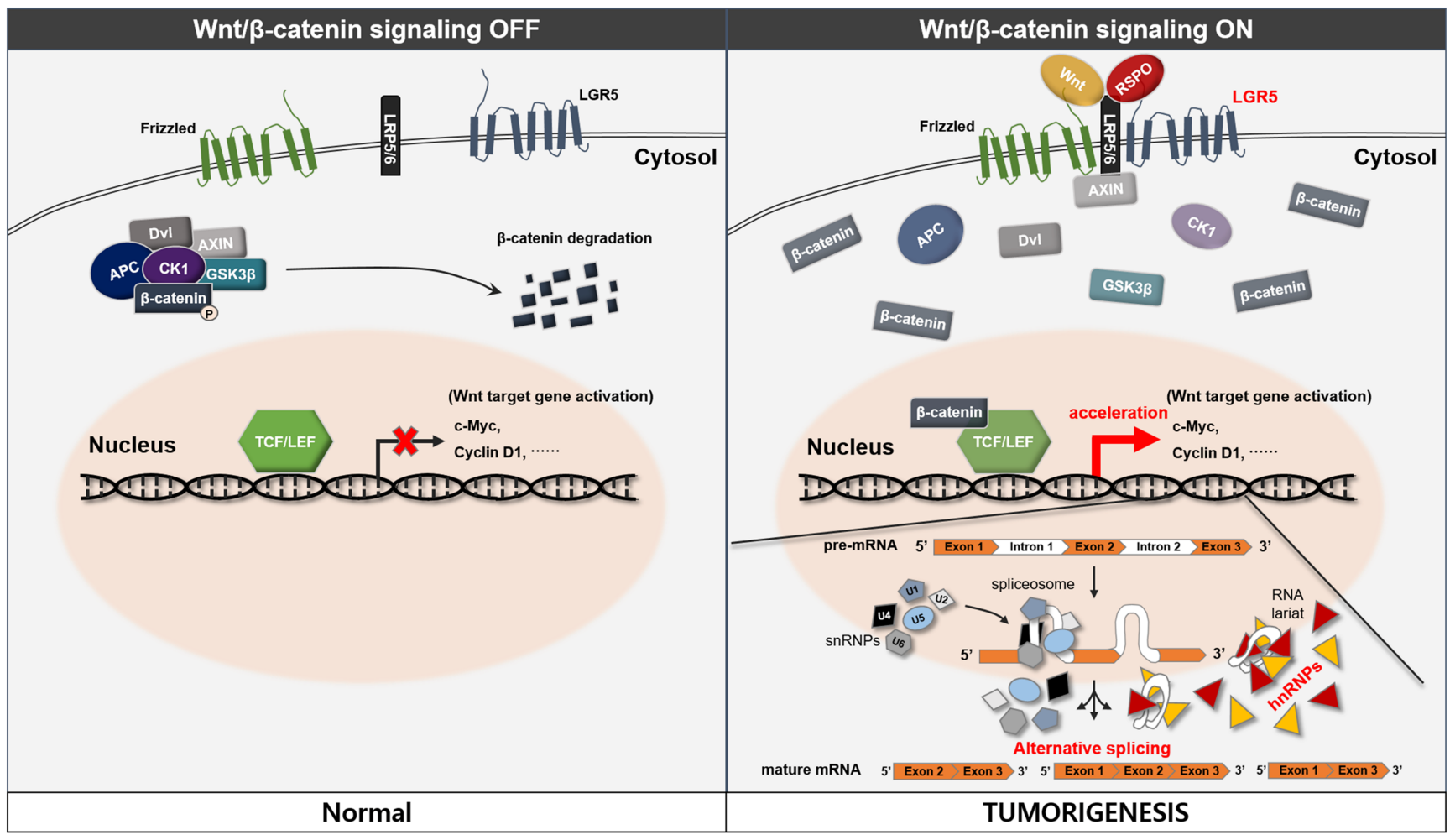

Fig. 7. Proposed mechanisms for the role of LGR5 and hnRNP in human meningioma and pituitary adenoma. The left panel shows the OFF state of the canonical Wnt/ $\beta$-catenin signaling. R-spondin-mediated activation of LGR5 promotes Wnt/ $\beta$-catenin signaling (right panel). This process leads to stabilization of $\beta$-catenin, which interacts with TCF/LEF proteins in the nucleus and together they activate Wnt target genes. We suggest that activation of Wnt target genes may also affect activation of the hnRNP family. This process may lead to hyperactivation of alternative gene transcription, splicing, and post-transcriptional modification of pre-mRNA processing in human meningioma and pituitary adenoma.

to believe that the activation of Wnt target genes by LGR5 activation may also affect activation of the hnRNP family (Fig. 7). This process may lead to hyperactivation of alternative pre-mRNA processing in brain tumors. To the best of our knowledge, this is the first study to demonstrate alterations in protein expression following knockdown of LGR5 in neuroblastoma cells and the identification of representative proteins affected by LGR5 inhibition in human brain tumor tissues. To improve our understanding on the roles of the signaling proteins affected by $L G R 5$ knockdown in neuroblastoma, meningioma, and pituitary adenoma, it would be helpful to investigate the previously known roles of these proteins.

Activation of the Wnt $/ \beta$-catenin pathway can upregulate $c$-myc expression [23], and a recent study suggested that hnRNP-K is a potential downstream signaling protein involved in the Wnt/ c-Myc pathway [24]. Therefore, we hypothesized that downregulation of Wnt/ $\beta$-catenin signaling by $L G R 5$ knockdown may affect members of the hnRNP family. Based on this hypothesis and because Wnt/ $\beta$-catenin is associated with meningioma and pituitary adenoma, our observations, which showed higher hnRNP in meningioma and pituitary adenoma (Fig. 5), may be under- standable [4]. Due to the lack of studies regarding the association between hnRNP and meningioma or pituitary adenoma, further study will be required to reinforce our findings. Furthermore, increasing evidence suggests that elevated hnRNPA2/B1 levels in tumors can accelerate pre-mRNA processing by promoting RNA binding, indicating a critical role of hnRNPA2/B1 in carcinogenesis, including neuroblastoma and glioblastoma $[25,26]$. Similar to hnRNPA2/B1, hnRNPH3 belongs to the hnRNP subfamily and displays similar functions including gene transcription, splicing, and post-transcriptional modification of pre-mRNA [27]. Interestingly, a previous study showed that knockdown of hnRNPA2 inhibits the Ras-MEK-ERK pathway and prevents ERK1/2 activation by epidermal growth factor [28]. Therefore, we hypothesized that decreased expression of proteins in the hnRNP family in neuroblastoma cells after $L G R 5$ knockdown may inhibit the RasMEK-ERK pathway. Indeed, the inhibition of the Ras-MEK-ERK pathway may be associated with Wnt-independent apoptosis in neuroblastoma cells, which was reported in a previous study [7]. Another study reported that high expression of RNA splicing factors is significantly associated with poor overall survival of 
patients with high-grade neuroblastoma, and the authors of the study suggested that key splicing factors may represent potential therapeutic targets in high-risk neuroblastoma patients [29].

$L G R 5$ knockdown down-regulates $\mathrm{Wnt} / \beta$-catenin signaling in neuroblastoma [7]. In the present study, we identified two proteins (prohibitin and PDIA3) associated with Wnt/ $\beta$-catenin signaling that were specifically decreased by LGR5 knockdown in neuroblastoma cells.

We also found that $L G R 5$ knockdown resulted in altered expression of the cytoskeletal proteins alpha-tubulin and beta-actin. We hypothesized that the increased expression of beta-actin was a compensatory mechanism as a result of the decreased expression of alpha-tubulin after $L G R 5$ knockdown in order to maintain cytoskeleton structure.

Lastly, we found that expression of $\alpha$-internexin was increased by LGR5 knockdown while expression of EF-Tu and peroxiredoxin 3 was decreased. EF-Tu is associated with protein synthesis as a regulator of translational accuracy and also regulates bacterial cytoskeleton integrity [30,31]. Peroxiredoxin 3, which is induced by oxidative stress, plays a critical role in protecting cells from cytotoxicity caused by oxidative stress, including mitochondrial dysfunction induced by reactive oxygen species [32] . a-Internexin is known as a neuron-specific intermediate filament protein and is considered to be the primary component of neuronal intermediate filaments [33].

There are limitations associated with the study. First, the initial utilization of neuroblastoma cells instead of using meningioma or pituitary adenoma cell lines may limit our findings. However, several clinical reports showed possible associations between neuroblastoma, and meningioma and pituitary adenoma. A previous study reported meningioma development after radiotherapy for an olfactory neuroblastoma at the same site [34]. The authors described that growth factor/cytokine release (such as insulinlike growth factor 1) by olfactory neuroblastoma has been linked to the oncogenesis of meningiomas [35-37]. In addition, previous studies have reported cases of neuroblastoma arising in the sellar region, and suggested that it mimicked a non-functioning pituitary adenoma [38-41]. Second, LGR5 knockdown with siRNA in SH-SY5Y neuroblastoma cells showed only approximately 50\% efficiency, and this relatively low knockdown efficiency of LGR5 may affect the results. However, several studies have also reported a similar siRNA knockdown efficiency [42-45]. Third, there were significant differences in the LGR5 expression between each tumor sample. However, the tumor samples showing relatively low LGR5 expressions showed higher LGR5 expressions compared to normal brain samples.

In conclusion, we identified a total of 12 proteins whose expres- sion was altered by LGR5 knockdown in SH-SY5Y neuroblastoma cells, four were upregulated and eight were downregulated. Among the identified proteins, HSP90 $\beta$ is known to interact with many different proteins, while decreased expression of hnRNP subfamily proteins by LGR5 knockdown may act to inhibit the RasMEK-ERK pathway, which may, in turn, induce apoptosis of neuroblastoma cells. In addition, we identified higher hnRNP family protein expression in meningioma and pituitary adenoma tissues. We think that our results may suggest a possible connection between LGR5 and its downstream signaling and neuroblastoma and brain tumors such as meningioma and pituitary adenoma. We hypothesized that activation of Wnt/ $\beta$-catenin signaling by LGR5 activation may activate the hnRNP family and this process may result in hyperactivation of alternative pre-mRNA processing in human meningioma and pituitary adenoma. Indeed, given the lack of previous studies regarding the association between LGR5 and neural tumor cells, we expect that our findings may enhance understanding on the association of LGR5 and its downstream signaling proteins with neuroblastoma and possibly brain tumors.

\section{ACKNOWLEDGEMENTS}

This research was supported by the Basic Science Research Program of the National Research Foundation of Korea, which is funded by the Ministry of Science, ICT, and Future Planning (2018R1D1A1B07047722, 2018R1A2A2A15023219, and 2018R1D1A1A09082825); funded by the Ministry of Health \& Welfare, Republic of Korea (grant number: HI18C1254), and by the Medical Research Center (2017R1A5A2015395).

\section{REFERENCES}

1. Lin Y, Fang ZP, Liu HJ, Wang LJ, Cheng Z, Tang N, Li T, Liu T, Han HX, Cao G, Liang L, Ding YQ, Zhou WJ (2017) HGF/Rspondin 1 rescues liver dysfunction through the induction of Lgr5+ liver stem cells. Nat Commun 8:1175.

2. Satoh J, Obayashi S, Tabunoki H, Wakana T, Kim SU (2010) Stable expression of neurogenin 1 induces LGR5, a novel stem cell marker, in an immortalized human neural stem cell line HB1.F3. Cell Mol Neurobiol 30:415-426.

3. Scannell CA, Pedersen EA, Mosher JT, Krook MA, Nicholls LA, Wilky BA, Loeb DM, Lawlor ER (2013) LGR5 is expressed by Ewing sarcoma and potentiates Wnt/ $\beta$-catenin signaling. Front Oncol 3:81.

4. Howng SL, Wu CH, Cheng TS, Sy WD, Lin PC, Wang C, Hong YR (2002) Differential expression of Wnt genes, beta-catenin and E-cadherin in human brain tumors. Cancer Lett 183:95- 
101.

5. Li J, Zhang Y, Cheng N, Zhao Q, Liu H, Song S (2016) The overexpression of leucine-rich repeat-containing g-proteincoupled receptor 5 in pituitary adenomas. Transl Surg 1:3740 .

6. Maris JM, Hogarty MD, Bagatell R, Cohn SL (2007) Neuroblastoma. Lancet 369:2106-2120.

7. Vieira GC, Chockalingam S, Melegh Z, Greenhough A, Malik S, Szemes M, Park JH, Kaidi A, Zhou L, Catchpoole D, Morgan R, Bates DO, Gabb PD, Malik K (2015) LGR5 regulates pro-survival MEK/ERK and proliferative Wnt/ $\beta$-catenin signalling in neuroblastoma. Oncotarget 6:40053-40067.

8. Gaston-Massuet C, Andoniadou CL, Signore M, Jayakody SA, Charolidi N, Kyeyune R, Vernay B, Jacques TS, Taketo MM, Le Tissier P, Dattani MT, Martinez-Barbera JP (2011) Increased Wingless (Wnt) signaling in pituitary progenitor/ stem cells gives rise to pituitary tumors in mice and humans. Proc Natl Acad Sci U S A 108:11482-11487.

9. Pećina-Šlaus N, Kafka A, Lechpammer M (2016) Molecular genetics of intracranial meningiomas with emphasis on canonical Wnt signalling. Cancers (Basel) 8:E67.

10. IARC International Agency for Research on Cancer (2017) WHO classification of tumours of endocrine organs. 4th ed. World Health Organization, Lyon.

11. Louis DN, Ohgaki H, Wiestler OD, Cavenee WK (2016) WHO classification of tumours of the central nervous system. International Agency for Research On Cancer, Lyon.

12. Hong EH, Hwang M, Shin YU, Park HH, Koh SH, Cho H (2018) Leucine-rich G protein-coupled receptor-5 is significantly increased in the aqueous humor of human eye with proliferative diabetic retinopathy. Exp Neurobiol 27:238-244.

13. Lee J, Park HH, Koh SH, Choi H (2017) Neural stem cell death mechanisms induced by amyloid beta. Dement Neurocogn Disord 16:121-127.

14. Fernandez J, Gharahdaghi F, Mische SM (1998) Routine identification of proteins from sodium dodecyl sulfate-polyacrylamide gel electrophoresis (SDS-PAGE) gels or polyvinyl difluoride membranes using matrix assisted laser desorption/ ionization-time of flight-mass spectrometry (MALDI-TOFMS). Electrophoresis 19:1036-1045.

15. Szklarczyk D, Franceschini A, Wyder S, Forslund K, Heller D, Huerta-Cepas J, Simonovic M, Roth A, Santos A, Tsafou KP, Kuhn M, Bork P, Jensen LJ, von Mering C. (2015) STRING v10: protein-protein interaction networks, integrated over the tree of life. Nucleic Acids Res 43:D447-D452.

16. Huelga SC, Vu AQ, Arnold JD, Liang TY, Liu PP, Yan BY, Donohue JP, Shiue L, Hoon S, Brenner S, Ares M Jr, Yeo GW
(2012) Integrative genome-wide analysis reveals cooperative regulation of alternative splicing by hnRNP proteins. Cell Rep 1:167-178.

17. Dvinge H, Kim E, Abdel-Wahab O, Bradley RK (2016) RNA splicing factors as oncoproteins and tumour suppressors. Nat Rev Cancer 16:413-430.

18. Baron R, Kneissel M (2013) WNT signaling in bone homeostasis and disease: from human mutations to treatments. Nat Med 19:179-192.

19. Lee Y, Lee JK, Ahn SH, Lee J, Nam DH (2016) WNT signaling in glioblastoma and therapeutic opportunities. Lab Invest 96:137-150.

20. Wang D, Zhou J, Fan C, Jiao F, Liu B, Sun P, Miao J, Zhang Q (2014) Knockdown of LGR5 suppresses the proliferation of glioma cells in vitro and in vivo. Oncol Rep 31:41-49.

21. Nakata S, Campos B, Bageritz J, Bermejo JL, Becker N, Engel F, Acker T, Momma S, Herold-Mende C, Lichter P, Radlwimmer B, Goidts V (2013) LGR5 is a marker of poor prognosis in glioblastoma and is required for survival of brain cancer stem-like cells. Brain Pathol 23:60-72.

22. Sakka L, Delétage N, Chalus M, Aissouni Y, Sylvain-Vidal V, Gobron S, Coll G (2017) Assessment of citalopram and escitalopram on neuroblastoma cell lines. Cell toxicity and gene modulation. Oncotarget 8:42789-42807.

23. Zhang S, Li Y, Wu Y, Shi K, Bing L, Hao J (2012) Wnt/ $\beta$-catenin signaling pathway upregulates c-Myc expression to promote cell proliferation of P19 teratocarcinoma cells. Anat Rec (Hoboken) 295:2104-2113.

24. Kawasaki Y, Komiya M, Matsumura K, Negishi L, Suda S, Okuno M, Yokota N, Osada T, Nagashima T, Hiyoshi M, Okada-Hatakeyama M, Kitayama J, Shirahige K, Akiyama T (2016) MYU, a target lncRNA for Wnt/c-Myc signaling, mediates induction of CDK6 to promote cell cycle progression. Cell Rep 16:2554-2564.

25. Deng J, Chen S, Wang F, Zhao H, Xie Z, Xu Z, Zhang Q, Liang P, Zhai X, Cheng Y (2016) Effects of hnRNP A2/B1 knockdown on inhibition of glioblastoma cell invasion, growth and survival. Mol Neurobiol 53:1132-1144.

26. Liang Y, Shi SL, Li QF, Chen LY, Jing GJ, Tan GW, Wang SY, Wu FY (2011) The localization of hnRNP A2/B1 in nuclear matrix and the aberrant expression during the RA-induced differentiation of human neuroblastoma SK-N-SH cells. J Cell Biochem 112:1722-1729.

27. Wang E, Aslanzadeh V, Papa F, Zhu H, de la Grange P, Cambi F (2012) Global profiling of alternative splicing events and gene expression regulated by hnRNPH/F. PLoS One 7:e51266. 28. Shilo A, Ben Hur V, Denichenko P, Stein I, Pikarsky E, Rauch 
J, Kolch W, Zender L, Karni R (2014) Splicing factor hnRNP A2 activates the Ras-MAPK-ERK pathway by controlling ARaf splicing in hepatocellular carcinoma development. RNA 20:505-515.

29. Zhang S, Wei JS, Li SQ, Badgett TC, Song YK, Agarwal S, Coarfa C, Tolman C, Hurd L, Liao H, He J, Wen X, Liu Z, Thiele CJ, Westermann F, Asgharzadeh S, Seeger RC, Maris JM, Guidry Auvil JM, Smith MA, Kolaczyk ED, Shohet J, Khan J (2016) MYCN controls an alternative RNA splicing program in high-risk metastatic neuroblastoma. Cancer Lett 371:214-224.

30. Wohlgemuth I, Pohl C, Mittelstaet J, Konevega AL, Rodnina MV (2011) Evolutionary optimization of speed and accuracy of decoding on the ribosome. Philos Trans R Soc Lond B Biol Sci 366:2979-2986.

31. Defeu Soufo HJ, Reimold C, Breddermann H, Mannherz HG, Graumann PL (2015) Translation elongation factor EF-Tu modulates filament formation of actin-like MreB protein in vitro. J Mol Biol 427:1715-1727.

32. Nishinaka Y, Masutani H, Nakamura H, Yodoi J (2001) Regulatory roles of thioredoxin in oxidative stress-induced cellular responses. Redox Rep 6:289-295.

33. Zhao J, Liem RKH (2016) a-internexin and peripherin: expression, assembly, functions, and roles in disease. In: Methods in enzymology (Omary MB, Liem RKH, eds), pp 477507. Academic Press, Cambridge, MA

34. Johnson MD, Piech K, Emandian S (2013) Radiation-associated meningioma in the elderly: development of meningioma with olfactory neuroblastoma recurrence 10 years after irradiation. Ann Clin Lab Sci 43:460-463.

35. Sandberg-Nordqvist AC, Ståhlbom PA, Reinecke M, Collins VP, von Holst H, Sara V (1993) Characterization of insulinlike growth factor 1 in human primary brain tumors. Cancer Res 53:2475-2478.

36. Yee D, Favoni RE, Lebovic GS, Lombana F, Powell DR, Reynolds CP, Rosen N (1990) Insulin-like growth factor I expres- sion by tumors of neuroectodermal origin with the $t(11 ; 22)$ chromosomal translocation. A potential autocrine growth factor. J Clin Invest 86:1806-1814.

37. Johnson M, Toms S (2005) Mitogenic signal transduction pathways in meningiomas: novel targets for meningioma chemotherapy? J Neuropathol Exp Neurol 64:1029-1036.

38. Whee SM, Lee JI, Kim JH (2002) Intrasellar schwannoma mimicking pituitary adenoma: a case report. J Korean Med Sci 17:147-150.

39. Dupuy M, Bonneville F, Grunenwald S, Breibach F, Delisle MB, Chaynes P, Sol JC, Caron P (2012) Primary sellar neuroblastoma. A new case and review of literature. Ann Endocrinol (Paris) 73:216-221.

40. Schmalisch K, Psaras T, Beschorner R, Honegger J (2009) Sellar neuroblastoma mimicking a pituitary tumour: case report and review of the literature. Clin Neurol Neurosurg 111:774778.

41. Oyama K, Yamada S, Usui M, Kovacs K (2005) Sellar neuroblastoma mimicking pituitary adenoma. Pituitary 8:109-114.

42. Prechtel AT, Turza NM, Theodoridis AA, Steinkasserer A (2007) CD83 knockdown in monocyte-derived dendritic cells by small interfering RNA leads to a diminished T cell stimulation. J Immunol 178:5454-5464.

43. Kobayashi M, Chandrasekhar A, Cheng C, Martinez JA, Ng H, de la Hoz C, Zochodne DW (2017) Diabetic polyneuropathy, sensory neurons, nuclear structure and spliceosome alterations: a role for CWC22. Dis Model Mech 10:215-224.

44. Shi YA, Zhao Q, Zhang LH, Du W, Wang XY, He X, Wu S, Li YL (2014) Knockdown of hTERT by siRNA inhibits cervical cancer cell growth in vitro and in vivo. Int J Oncol 45:12161224.

45. Bruneau S, Néel M, Roumenina LT, Frimat M, Laurent L, Frémeaux-Bacchi V, Fakhouri F (2015) Loss of DGKe induces endothelial cell activation and death independently of complement activation. Blood 125:1038-1046. 